\title{
O espaço de entrecruzamento das palavras: a relação médico-paciente
}

The intersection space of words: the doctor-patient relationship

\section{El espacio de la intersección de las palabras: la relación médico-paciente}

Armando Henrique Norman, MSc. Médico de Família e Comunidade. Departamento de Antropologia, Universidade de Durham. Durham, Reino Unido. a.h.norman@durham.ac.uk (Autor correspondente)

Livros e revistas oferecem apenas ideias genéricas, esboços (mais ou menos bem sucedidos) das correntes gerais na vida do mundo, mas não podem dar a impressão direta, imediata e vivida da vida de Pedro, Paulo e João, dos únicos e reais individuos e, a não ser que se possa entendê-los, não se poderá compreender o que está sendo universalizado e generalizado. (p. 165)

Antonio Gramsci ${ }^{1}$
A Revista Brasileira de Medicina de Família e Comunidade (RBMFC) nesta edição especial de Volume 10 número 35, aborda o tema da Prevenção Quaternária (P4), que passou a fazer parte dos descritores da Bireme (DeCS) em 06/04/2015, graças a iniciativa da RBMFC., Assim, novas palavras começam a ganhar forma e força como discurso contra-hegemônico dentro da própria medicina por meio da 'liderança moral e intelectual' ${ }^{\prime 4}$ de pesquisadores e médicos práticos. A ilustração da capa, intitulada 'Palavras da Prevençáo' faz referência à importância de certos termos no campo da prevenção, bem como aos vários temas discutidos na presente edição. De certa forma, é por meio da linguagem e do uso das palavras que se sustenta a prática da medicina de família, calcada na relação médico-paciente. Esta se constitui como um dos cernes da especialidade e tem a palavra como potencializadora de atividades de prevenção quaternária. As palavras, muitas vezes, podem causar iatrogenia, ao se rotular ou transformar potenciais riscos em 'doença', e assim gerar dúvidas e medos nos pacientes pela produção de pseudodoenças. Mas é também por meio das palavras que se pode tranquilizar e produzir efeitos terapêuticos positivos nos pacientes. Portanto, a palavra como um dos pilares da comunicação, necessita ser adequadamente trabalhada para facilitar o entendimento entre profissionais de saúde e pacientes durante a troca de informaçóes. É a partir da relação médico-paciente, espaço de entrecruzamento das palavras, que se constrói no cotidiano a prevenção quaternária.

A presente edição especial é uma construção coletiva liderada brilhantemente pelo editor convidado, Dr. Marc Jamoulle, idealizador do conceito da P4. O entusiasmo e dinamismo do Dr. Jamoulle em fortalecer uma rede internacional de pesquisadores e médicos de família preocupados com os excessos da medicina foi fundamental para a materialização desta edição. Se da dimensão epidemiológica e dos ensaios clínicos surgiram provas científicas quanto aos efeitos danosos do sobrediagnóstico e sobretratamento, foi do campo da prática dos médicos de família que surgiu o conceito da prevenção quaternária. Hoffman e Wilkes afirmam que a 'P4 oferece um novo paradigma, ao insistir que o dano médico está longe de ser algo trivial ou uma preocupação secundária’. A prevenção quaternária é a resposta

Como citar: Norman AH. O espaço de entrecruzamento das palavras: a relação médico-paciente.
Fonte de financiamento: declara não haver. Parecer CEP: não se aplica.

Conflito de interesses: declara não haver.

Recebido em: 21/05/2015. Aprovado em: 22/05/2015. 
prática, concreta e possível para o enfrentamento cotidiano de uma epidemia iatrogênica velada resultante do intervencionismo da biomedicina e do domínio da informação. Nesse sentido, esta edição aborda alguns dos temas relativos à prática médica ao discutir os fenômenos decorrentes dos excessos da medicina, rotulados pelo prefixo em inglês 'over'.

A seção de artigos originais inicia a temática da P4 no campo da semântica com os artigos de Jamoulle et al. The words of prevention, part I: changing the model e The words of prevention, part II: ten terms in the realm of quaternary prevention. O primeiro artigo revisita os conceitos e definiçôes das prevençôes primária, secundária, terciária e quaternária destacando a necessidade de mudança de paradigma de uma perspectiva temporal-linear para uma perspectiva co-construtivista, fundamentada na relação com o outro. Já o segundo artigo, sinaliza para a necessidade da inclusão nas bases de dados científicas de termos importantes para o campo da medicina, tais como: sobrediagnóstico e sobretratamento, incidentalomas, sobrerrastreamento, desprescrição, sobremedicalização, entre outros. Alguns desses termos mereceram aprofundamento: Gómez Santana et al. discorrem sobre o uso criterioso da desprescrição como medida de prevençáo quaternária; Pizzanelli define e aborda questôes importantes relativas ao tema do sobrerrastreamento; e Mariño traz uma revisão sobre o tema dos incidentalomas e suas implicações na prática médica. Já Cardoso, discute e contextualiza o tema da medicalização (e sobremedicalização) e os desafios da prática da $\mathrm{P} 4$, visto que de certa forma, todos esses neologismos têm como base o excesso da prática e da extrapolação da 'jurisdição' médica.

Um dos campos mais sensíveis de medicalização é o da saúde mental. Sendo assim, Lobo e Bernstein discutem as particularidades e desafios na abordagem dos pacientes em sofrimento psíquico. Os autores questionam o potencial de danos, tanto das abordagens psicoterápicas como medicamentosas, e oferecem algumas alternativas a serem consideradas, tais como o fortalecimento da relação médico-paciente e a desprescrição. Como exemplo dos riscos da medicalização no campo da saúde mental, Jean-Claude St-Onge faz uma análise crítica do transtorno de déficit de atenção e hiperatividade (TDAH) alertando sobre os riscos e potenciais consequências do sobrediagnóstico e do sobretratamento. Ainda no campo da medicalizaçáo, Tesser et al. discutem o tema da violência obstétrica no Brasil e as taxas escandalosas de cesarianas, além de proporem alternativas de açôes de P4, tanto a nível da Atenção Primária à Saúde (APS) como a nível institucional.

Nas dimensôes epistemológica, filosófica e ética da P4, esta edição especial nos convida a refletir e a pensar alternativas tanto na prática da medicina como nas atividades acadêmicas. Assim, Widmer fornece as bases filosóficas da P4 como subsídio ao pensamento crítico sobre o conhecimento médico (Epistemologia) e as açóes em saúde (Ética). Perpassando esse tema, Mangin e Heath ressaltam a importância da prevenção quaternária frente a pacientes com quadro clínicos múltiplos e complexos, em que modelos ou protocolos fundamentados em uma abordagem de doença-única são poucos efetivos e potencialmente danosos. Por outro lado, Wagner et al. apontam para os conflitos de interesses na construção das evidências científicas e na manipulação dos dados de pesquisas para favorecer os interesses das corporaçôes do setor farmacológico e do complexo médico hospitalar. Por sua vez, Yver discute a influência da biotecnologia e do complexo fármaco-industrial na área da patologia clínica para estabelecer pontos de corte da positividade do teste imunohistoquímico HER-2 e o uso do Herceptin (Trastuzumab) para tratamento do câncer de mama. Fazendo um contraponto à produção científica em medicina, De Jonghe traz um relato de experiência da aplicação da prevenção quaternária como um guia para o corpo editorial de uma revista de Medicina Baseada em Evidência (MBE), destacando a responsabilidade ética e os desafios na produçáo de conhecimento na área da saúde.

$\mathrm{Na}$ prática educativa e acadêmica da medicina, Tran e Vo discutem o impacto da introdução da P4 para estudantes do quinto ano do curso de medicina da universidade de Pham Ngoc Thach, Hochiminh, Vietnâ. Os autores ressaltam o potencial positivo de mudança de comportamento na prática dos estudantes ao assimilarem os conceitos da P4. Em uma perspectiva de fortalecimento da prevenção quaternária como conteúdo médico-acadêmico, Gomes et al. propóem um guia teórico-prático para a implementação da $\mathrm{P} 4$ na formação de médicos, tanto na graduação como nos programas de residência em medicina de família. Por fim, Norman e Tesser fundamentam uma proposta de operacionalização da P4 na relação médico-paciente, estruturada por meio do modelo de consulta aprimorado de Calgary-Cambridge. $\mathrm{O}$ artigo pretende criar uma base conceitual e instrumental para facilitar a inclusão da P4 na consulta dos médicos de família, que uma vez internalizada poderia contribuir para diminuir os excessos da medicina.

A organicidade intelectual de Gramsci, exemplificada na epígrafe deste editorial, tem forte paralelo com a prática da medicina de família, visto que esta sempre desconfiou das generalizações e da universalização da biomedicina. Com o advento da MBE ocorreu uma proeminência de estudos populacionais, que de certa forma amplificou o pensamento abstrato, tornando anônimos os pacientes. Exemplo disso está no 'Índice de Sobretratamento' como ferramenta útil para a medicina de família na tomada de decisão clínica, descrito por Pezeshki e Pezeshki. Esse novo contexto agora requer do médico prático 
saberes específicos que possam fortalecer uma prática médica dialógica entre os polos 'objetivos' e 'subjetivos' do encontro clínico. ${ }^{5} \mathrm{O}$ primeiro se refere à construção do saber biomédico e à materialidade dos corpos, o segundo à particularidade dos indivíduos, na sua dimensão biopsicossocial. A prevenção quaternária tem como parâmetro para intervençôes médicas a relação com o paciente, tanto nos seus aspectos subjetivos como objetivos, ao mesmo tempo em que desmistifica o saber médico ao situá-lo como um instrumento subserviente à dimensão humana.

Por fim, esta edição evidencia o processo de aprimoramento da RBMFC, que cada vez mais se define como um periódico voltado para as questóes da MFC e da APS, dialogando internacionalmente com seus pares na busca por alternativas éticas à pesquisa e à prática em medicina. Esta edição também revela o caráter independente do periódico, visando contribuir para o conhecimento dos profissionais da área da APS, bem como de leitores interessados na temática da saúde e dos abusos do setor das indústrias fármaco-biomédicas. A RBMFC, portanto, mantém seu compromisso com os médicos de família, com os profissionais da saúde e acadêmicos envolvidos na construçáo de uma APS forte e de sistemas públicos de saúde de qualidade, ao produzir esta edição especial sobre a prevenção quaternária.

\section{Referências}

1. Crehan K. Gramsci, culture and anthropology. London: Pluto Press; 2002.

2. Pan-American Health Organization (OPAS); World Health Organization (WHO). Já está disponível a versão 2015 do DeCS. Brasília: OPAS; 2015 [acesso em 2015 May 21]. Disponível em:

http://www.paho.org/bireme/index.php?option=com_content\&view=article\&id=283\%3Aja-esta-disponivel-a-versao-2015-do-decs\&ltemid=73\&lang=pt

3. Pan-American Health Organization (OPAS); World Health Organization (WHO). DeCS 2015 - Novidades. Brasilia: OPAS; 2015 [acesso em 2015 May 21]. Disponível em: http://decs.bvs.br/P/visaogeral2015.htm

4. Kurtz DV. Hegemony anthropology: gramsci, exegeses, reinterpretations. Crit Anthropol. 1996;16(2):103-35. http://dx.doi.org/10.1177/0308275X9601600202.

5. Heath I. Arm in arm with righteousness. Philos Ethics Humanit Med. 2015;10(7):1-4. http://dx.doi.org/10.1186/s13010-015-0024-y. PMid:25903168. 